\title{
Rakicidin D, an inhibitor of tumor cell invasion from marine-derived Streptomyces sp.
}

\author{
Yasuhiro Igarashi $^{1}$, Ryoko Shimasaki ${ }^{1}$, Satoshi Miyanaga ${ }^{1}$, Naoya Oku ${ }^{1}$, Hiroyasu Onaka ${ }^{1}$, Hiroaki Sakurai ${ }^{2}$, \\ Ikuo Saiki $^{2}$, Shigeru Kitani ${ }^{3}$, Takuya Nihira ${ }^{3,5}$, Waurawan Wimonsiravude ${ }^{4,5}$ and Watanalai Panbangred ${ }^{4,5}$
}

The Journal of Antibiotics (2010) 63, 563-565; doi:10.1038/ja.2010.70; published online 30 June 2010

Keywords: invasion inhibitor; rakicidin; Streptomyces

Tumor metastasis is the leading cause of death in cancer patients. It is the process by which a tumor cell leaves the primary tumor, disseminates to a distant site through the circulatory system and establishes a secondary tumor. ${ }^{1}$ During the metastatic cascade, tumor cells must pass through the extracellular matrix barriers to accomplish the metastasis. Although the genetic basis of tumorigenesis can vary greatly, the steps required for metastasis are similar for all tumor cells. Therefore, interruption of metastasis is a promising approach to the treatment of cancers of various genetic origins. In our continuing search for anti-invasive compounds from microbial secondary metabolites, ${ }^{2-5}$ rakicidin D (1) was isolated from the culture broth of an actinomycete strain of the genus Streptomyces. Rakicidins are the 15-membered depsipeptides consisting of three amino acids and a 3-hydroxyfatty acid (Figure 1). To date, three congeners, rakicidins A (2) and B (3) from Micromonospora and rakicidin C (4) from Streptomyces, have been reported. ${ }^{6,7}$ Rakicidins contain a rare unusual amino acid, 4-amino-2,4-pentadienoate, which has been found only in the secondary metabolites from actinomycetes. Except for rakicidins, only two classes of cyclic peptides, $\mathrm{BE} 43547^{8}$ and vinylamycin, ${ }^{9}$ are reported to date to contain this unusual amino acid. Herein, we describe the isolation, structure elucidation and biological properties of rakicidin D (1).

The producing strain Streptomyces sp. MWW064 was isolated from a marine sediment sample collected in Samut Sakhon province, Thailand. The strain was cultured in our standard medium for actinomycetes and the whole culture broth was extracted with 1-butanol. The extract showed inhibitory activity toward tumor cell invasion into Matrigel, the reconstituted extracellular matrix proteins. ${ }^{10}$ Bioassay-guided fractionation of the extract led to the isolation of a new compound, rakicidin D (1).

Compound $\mathbf{1}$ was obtained as a colorless amorphous powder. The high-resolution ESITOFMS indicated a molecular formula of
$\mathrm{C}_{24} \mathrm{H}_{38} \mathrm{~N}_{4} \mathrm{O}_{7}$, which was consistent with the ${ }^{1} \mathrm{H}$ and ${ }^{13} \mathrm{C}$ NMR data. The IR spectrum of 1 indicated the presence of $\mathrm{OH}$ or $\mathrm{NH}$ $\left(3356 \mathrm{~cm}^{-1}\right)$ and carbonyl (1688 and $\left.1648 \mathrm{~cm}^{-1}\right)$ functionalities. The UV spectrum and the ${ }^{1} \mathrm{H}$ and ${ }^{13} \mathrm{C}$ NMR spectra of 1 showed high similarity to those for rakicidins $\mathrm{A}$ and $\mathrm{B} .{ }^{7}$ The ${ }^{13} \mathrm{C}$ NMR and HMQC analysis confirmed the presence of 24 carbons attributable to six deshielded signals including carbonyl carbons, two $\mathrm{sp}^{2}$ methines, one $\mathrm{sp}^{2}$ methylene, five $\mathrm{sp}^{3}$ methines, six $\mathrm{sp}^{3}$ methylenes, four methyl carbons and five exchangeable protons.

2-Amino-2,4-pentadienoate moiety was elucidated by a COSY correlation for $\mathrm{H}-9 / \mathrm{H}-10$ and a series of $\mathrm{HMBC}$ correlations from H-12 to C-10 and C-11, from H-10 to C-8, C-11 and C-12, and from $\mathrm{H}-9$ to $\mathrm{C}-8$ and C-10 (Figure 2). An NOE between H-10 and an exomethylene proton at $\delta_{\mathrm{H}} 5.41$ indicated that the latter proton and $\mathrm{C}-10$ were located on the same side of the $\mathrm{C}-11 / \mathrm{C}-12$ double bond. E configuration for the double bond between C-9 and C-10 was confirmed by a large coupling constant for $\mathrm{H}-9$ and $\mathrm{H}-10$ $\left({ }^{3} \mathrm{~J}_{\mathrm{HH}}=15.0 \mathrm{~Hz}\right)$. HMBC correlations from $\mathrm{H}-7$ to C-6 and C-8, and from $\mathrm{H}-6$ to $\mathrm{C}-5$ and C-8 established the connectivity of $\mathrm{N}$-methylglycine and the pentadienoate. COSY correlations for $2-\mathrm{NH} / \mathrm{H}-2 / \mathrm{H}-3$ and $\mathrm{HMBC}$ correlations from $\mathrm{H}-2$ to $\mathrm{C}-1, \mathrm{H}-3$ to $\mathrm{C}-4$ and $4-\mathrm{NH}_{2}$ to $\mathrm{C}-3$ confirmed the presence of a $\beta$-hydroxyasparagine moiety. Connection of this amino acid to the glycine moiety was established by an $\mathrm{HMBC}$ correlation from $2-\mathrm{NH}$ to $\mathrm{C}-5$. Three additional fragments, $\mathrm{H}-23 / \mathrm{H}-14 / \mathrm{H}-15, \mathrm{H}-24 / \mathrm{H}-16$ and $\mathrm{H}-21 / \mathrm{H}-22$, were recognized from the COSY spectrum. HMBC correlations from $\mathrm{H}-23$ to C-13, C-14 and C-15, and from $\mathrm{H}-24$ to C-15, C-16 and C-17, established the 2,4-dimethyl-3-hydroxyalkanoate substructure. Connectivity of this fragment to the peptide unit was elucidated by HMBC correlations from $11-\mathrm{NH}$ to $\mathrm{C}-13$ and from $\mathrm{H}-15$ to $\mathrm{C}-1$. Finally, the fragment C-22/C-21 containing the triplet methyl group, the methylene fragment C-20 that had an HMBC correlation from $\mathrm{H}-22$ and

\footnotetext{
${ }^{1}$ Biotechnology Research Center, Toyama Prefectural University, Imizu, Toyama, Japan; ${ }^{2}$ Department of Bioscience, Institute of Natural Medicine, Toyama University, Sugitani, Toyama, Japan; ${ }^{3}$ International Center for Biotechnology, Osaka University, Suita, Osaka, Japan; ${ }^{4}$ Faculty of Science, Department of Biotechnology, Mahidol University, Bangkok, Thailand and ${ }^{5}$ Mahidol University and Osaka University Collaborative Research Center on Bioscience and Biotechnology, Bangkok, Thailand Correspondence: Dr Y Igarashi, Biotechnology Research Center, Toyama Prefectural University, 5180 Kurokawa, Imizu, Toyama 939-0398, Japan. E-mail: yas@pu-toyama.ac.jp
} 


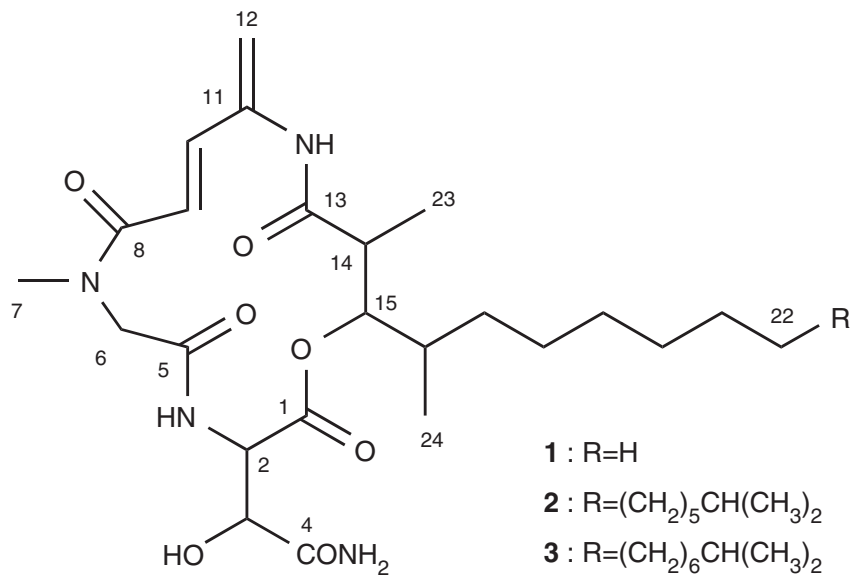<smiles>C=C(/C=C/C(=O)N(C)CC(=O)NC(CCC(N)=O)C(=O)OC(C(C)CC(C)CC(C)C)C(C)C(=O)NC(=O)CC(C)C)NC(=O)CC(C)C</smiles>

Figure 1 Structure of rakicidins D (1), A (2), B (3) and C (4).

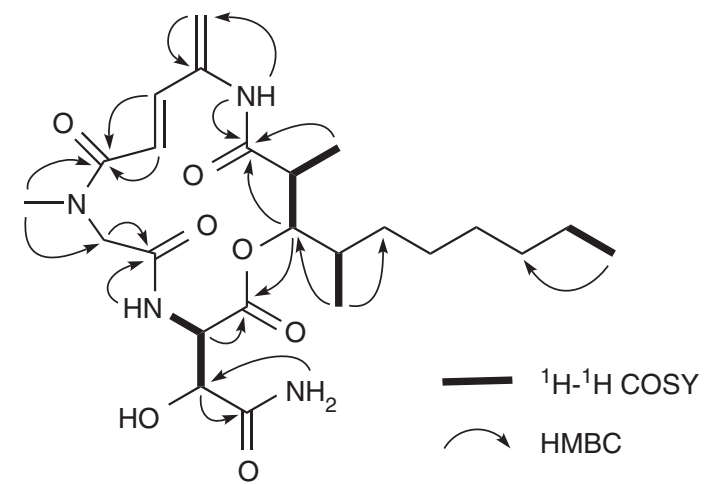

Figure $2{ }^{1} \mathrm{H}-{ }^{1} \mathrm{H}$ COSY and key HMBC correlations for 1 .

the remaining two $\mathrm{CH}_{2}$ fragments (C-18 and C-19) were assigned to the terminal linear moiety of the alkanoate to complete the planar structure of $\mathbf{1}$. Compound $\mathbf{1}$ has the same amino-acid components as rakicidins $\mathrm{A}$ and $\mathrm{B}$ but a shorter side chain with no terminal methyl branching in the fatty acid moiety.

Rakicidin D (1) inhibited the invasion of murine carcinoma colon 26-L5 cells with an $\mathrm{IC}_{50}$ of $3.3 \mu \mathrm{g} \mathrm{ml}^{-1}(=6.7 \mu \mathrm{M})$, whereas it showed no growth inhibition toward the same cell line at $10 \mu \mathrm{g} \mathrm{ml}^{-1} \cdot{ }^{10}$ Rakicidins A (2) and B (3), which were separately obtained from Micromonospora sp. TP-A0860. Rakicidin B was described to have an isopropyl terminus in the fatty acid moiety but also described to have 3-hydroxy-2,4,16-trimethyloctadecanoic acid (anteiso-terminus), while the NMR data for rakicidin B were not provided in the literature. We thus reisolated rakicidin $\mathrm{B}$ and unambiguously confirmed that it had an iso-terminus on the basis of NMR analysis (see Supplementary Information). Compounds $\mathbf{2}$ and $\mathbf{3}$ showed much higher cytotoxicity toward the same cell line $\left(\mathrm{IC}_{50}=0.44 \mu \mathrm{g} \mathrm{ml}^{-1}\right.$ and $0.17 \mu \mathrm{g} \mathrm{ml}^{-1}$ ), giving a suggestion that the alkyl side chain of the fatty acid moiety has a key role in cytotoxic effect. Anti-invasive effects of $\mathbf{2}$ and $\mathbf{3}$ were not observed at noncytotoxic concentrations.

\section{EXPERIMENTAL PROCEDURE}

\section{General experimental procedure}

Optical rotations were measured using a JASCO DIP-3000 polarimeter (JASCO, Tokyo, Japan). UV spectrum was recorded on a Hitachi U-3210 spectrophotometer (Hitachi, Ibaraki, Japan). IR spectrum was measured on a PerkinElmer Spectrum 100 (PerkinElmer, Waltham, MA, USA). NMR spectra were obtained on a Bruker AVANCE 400 or a Bruker AVANCE 500 spectrometer (Bruker, Bremen, Germany) in dimethyl sulfoxide- $d_{6}$ using the signals of the residual solvent protons $\left(\delta_{\mathrm{H}} 2.49\right)$ and carbons $\left(\delta_{\mathrm{H}} 39.8\right)$ as internal standard. HRESITOFMS were recorded on a Bruker microTOF focus.

\section{Microorganism}

Strain MWW064 was isolated from a sediment sample collected in Samut Sakhon province, Thailand. The strain was identified as a member of the genus Streptomyces on the basis of $99.0 \% 16 \mathrm{~S}$ rRNA gene sequence (1431 nucleotides; DDBJ, DNA Data Bank of Japan, accession number GU295447) identity with Streptomyces argenteolus subsp. toyonakensis NBRC13847 (accession number AB184528.1).

\section{Fermentation}

Strain MWW064 cultured on a slant agar medium was inoculated into 500-ml $\mathrm{K}-1$ flasks each containing $100 \mathrm{ml}$ of the $\mathrm{V}-22$ seed medium consisting of soluble starch $1 \%$, glucose $0.5 \%$, NZ-case $0.3 \%$, yeast extract $0.2 \%$, triptone (Difco Laboratories, Sparks, MD, USA) $0.5 \%, \mathrm{~K}_{2} \mathrm{HPO}_{4} 0.1 \%, \mathrm{MgSO}_{4} \cdot 7 \mathrm{H}_{2} \mathrm{O}$ $0.05 \%$ and $\mathrm{CaCO}_{3} 0.3 \%$ (pH 7.0). The flasks were cultivated on a rotary shaker (200 r.p.m.) at $30^{\circ} \mathrm{C}$ for 4 days. The seed culture $(3 \mathrm{ml})$ was transferred into $500-\mathrm{ml} \mathrm{K}-1$ flasks each containing $100 \mathrm{ml}$ of the A-3M production medium consisting of glucose $0.5 \%$, glycerol $2 \%$, soluble starch $2 \%$, Pharmamedia (Traders Protein, Memphis, TN, USA) $1.5 \%$, yeast extract $0.3 \%$ and Diaion HP-20 (Mitsubishi Chemical, Kanagawa, Japan) 1\%. The pH of the medium was adjusted to 7.0 before sterilization. The inoculated flasks were cultured on a rotary shaker $\left(200\right.$ r.p.m.) at $30^{\circ} \mathrm{C}$ for 6 days.

\section{Extraction and isolation}

At the end of the fermentation period, $50 \mathrm{ml}$ of 1-butanol was added to each flask, and they were allowed to shake for 1 additional hour. The mixture was centrifuged at 6000 r.p.m. for $10 \mathrm{~min}$ and the organic layer was separated from the aqueous layer containing the mycelium. Evaporation of the solvent gave $27.9 \mathrm{~g}$ of crude extract from 3 liter of culture. The crude extract $(27.9 \mathrm{~g})$ was subjected to silica gel column chromatography with a step gradient of $\mathrm{CHCl}_{3}-\mathrm{MeOH}(1: 0,20: 1,10: 1,4: 1,2: 1,1: 1$ and 0:1, v/v). Fractions six and seven were concentrated to provide $0.79 \mathrm{~g}$ of dark viscous oil, which was further purified by reversed phase octadecyl silane column chromatography with a gradient of MeCN-0.1\% $\mathrm{HCOOH}(2: 8,3: 7,4: 6,5: 5,6: 4,7: 3$ and 8:2, v/v). Fraction 4 (50:50) was evaporated and the remaining aqueous solution was lyophilized to afford $\mathbf{1}(66 \mathrm{mg})$ as a colorless amorphous solid. Production of metabolites analogous to rakicidins was not detected in the culture extract.

Rakicidin $D$ (1). Colorless amorphous solid; $[\alpha]_{D}^{23}-140$ (c 0.20, dimethyl sulfoxide); UV (30\% MeCN) $\lambda_{\max }$ (log $\left.\varepsilon\right) 207$ (4.57), 261 (4.18); IR (neat) $v_{\max }$ $3371,2930,1688,1648 \mathrm{~cm}^{-1} ;{ }^{1} \mathrm{H}$ and ${ }^{13} \mathrm{C}$ NMR data, see Table $1\left({ }^{1} \mathrm{H}\right.$ and ${ }^{13} \mathrm{C}$ NMR spectra are shown in Supplementary Figures S1 and S2 of Supplementary Information); HRESITOFMS [M-H] $]^{-} 493.2665$ (calcd for $\mathrm{C}_{24} \mathrm{H}_{37} \mathrm{~N}_{4} \mathrm{O}_{7}$, 493.2668). 
Table $1{ }^{1} \mathrm{H}$ and ${ }^{13} \mathrm{C}$ NMR data for rakicidin D (1) in DMSO- $d_{6}$

\begin{tabular}{|c|c|c|c|}
\hline Position & $\delta_{C}{ }^{a}$ & $\delta_{H}$ mult $(\mathrm{J} \text { in } \mathrm{Hz})^{\mathrm{b}}$ & $H M B C^{\mathrm{b}, \mathrm{c}}$ \\
\hline 1 & 169.2, qC & & \\
\hline 2 & $54.9, \mathrm{CH}$ & $4.88, \mathrm{dd}(10.0,1.8)$ & 1,3 \\
\hline 3 & $72.5, \mathrm{CH}$ & 4.18, br.s & 2,4 \\
\hline 4 & $172.7, \mathrm{qC}$ & & \\
\hline 5 & $167.6, \mathrm{qC}$ & & \\
\hline \multirow[t]{2}{*}{6} & $52.5, \mathrm{CH}_{2}$ & $4.46, d(18.2)$ & 5,7 \\
\hline & & $3.68, d(18.2)$ & $5,7,8$ \\
\hline 7 & $36.5, \mathrm{CH}_{3}$ & $2.94, \mathrm{~s}$ & 6,8 \\
\hline 8 & $166.0, \mathrm{qC}$ & & \\
\hline 9 & $118.8, \mathrm{CH}$ & $6.16, d(15.0)$ & 8,10 \\
\hline 10 & $137.9, \mathrm{CH}$ & $6.86, d(15.0)$ & $8,11,12$ \\
\hline 11 & $138.4, \mathrm{qC}$ & & \\
\hline \multirow[t]{2}{*}{12} & $117.1, \mathrm{CH}_{2}$ & $5.43, \mathrm{~s}$ & 11 \\
\hline & & $5.32, \mathrm{~s}$ & 10,11 \\
\hline 13 & $172.5, \mathrm{qC}$ & & \\
\hline 14 & 41.7, $\mathrm{CH}$ & $2.89, \mathrm{dq}(9.9,7.0)$ & $13,15,23$ \\
\hline 15 & $78.1, \mathrm{CH}$ & $5.11, d(9.9)$ & $1,13,14,24$ \\
\hline 16 & $33.9, \mathrm{CH}$ & $1.69, \mathrm{~m}$ & 24 \\
\hline \multirow[t]{2}{*}{17} & $32.8, \mathrm{CH}_{2}$ & $1.35, \mathrm{~m}$ & \\
\hline & & $1.13, \mathrm{~m}$ & \\
\hline \multirow[t]{2}{*}{18} & $27.0^{\mathrm{d}}, \mathrm{CH}_{2}$ & $1.32, \mathrm{~m}$ & \\
\hline & & $1.22, \mathrm{~m}$ & \\
\hline 19 & $28.9^{\mathrm{d}}, \mathrm{CH}_{2}$ & $1.22, \mathrm{~m}$ & \\
\hline 20 & $31.3, \mathrm{CH}_{2}$ & $1.22, \mathrm{~m}$ & \\
\hline 21 & $22.1, \mathrm{CH}_{2}$ & $1.26, \mathrm{~m}$ & \\
\hline 22 & $14.0, \mathrm{CH}_{3}$ & $0.85, \mathrm{t}(6.6)$ & 20,21 \\
\hline 23 & $15.4, \mathrm{CH}_{3}$ & $1.04, \mathrm{~d}(7.0)$ & $13,14,15$ \\
\hline 24 & $13.3, \mathrm{CH}_{3}$ & $0.93, d(6.8)$ & $15,16,17$ \\
\hline 2-NH & & 8.09, d (10.0) & 5 \\
\hline \multirow[t]{2}{*}{ 4- $\mathrm{NH}_{2}$} & & $7.31, \mathrm{~s}$ & 3 \\
\hline & & $7.29, \mathrm{~s}$ & 3 \\
\hline $11-\mathrm{NH}$ & & $8.90, \mathrm{~s}$ & 12,13 \\
\hline
\end{tabular}

${ }^{\text {aRecorded at }} 100 \mathrm{MHz}$.

bRecorded at $500 \mathrm{MHz}$

cHMBC correlations are from proton(s) stated to the indicated carbon.

IInterchangeable.

Isolation of rakicidins A and B. Rakicidins A (2) and B (3) were obtained from the culture extract of Micromonospora sp. TP-A0860. ${ }^{11}$
Rakicidin A (2). Colorless amorphous solid; $[\alpha]_{D}^{24}-126$ (c 0.10, dimethyl sulfoxide); ${ }^{1} \mathrm{H}$ and ${ }^{13} \mathrm{C}$ NMR data were identical with those reported in the literature; ${ }^{6}$ HRESITOFMS $[\mathrm{M}-\mathrm{H}]^{-} 605.3927$ (calcd for $\mathrm{C}_{32} \mathrm{H}_{53} \mathrm{~N}_{4} \mathrm{O}_{7}$, 605.3920).

Rakicidin B (3). Colorless amorphous solid; $[\alpha]^{22} \mathrm{D}-90$ (c 0.10 , dimethyl sulfoxide); ${ }^{1} \mathrm{H}$ NMR and ${ }^{13} \mathrm{C}$ NMR data, see Supplementary Table S1 in Supplementary Information $\left({ }^{1} \mathrm{H}\right.$ and ${ }^{13} \mathrm{C}$ NMR spectra are shown in Supplementary Figures S3 and S4 of Supplementary Information; described earlier). HRESITOFMS [M-H] $]^{-} 619.4072$ (calcd for $\mathrm{C}_{33} \mathrm{H}_{55} \mathrm{~N}_{4} \mathrm{O}_{7}$, 619.4076).

\section{ACKNOWLEDGEMENTS}

This research was supported in part by a research grant from Mahidol University to WP.
1 Geho, D. H., Bandle, R. W., Clair, T. \& Liotta, L. A. Physiological mechanisms of tumor-cell invasion and migration. Physiology 20, 194-200 (2005).

2 Igarashi, Y. et al. Brartemicin, an inhibitor of tumor cell invasion from the actinomycete Nonomuraea sp. J. Nat. Prod. 79, 980-982 (2009).

3 Miyanaga, S., Sakurai, H., Saiki, I., Onaka, H. \& Igarashi, Y. Anti-invasive and anti-angiogenic activities of naturally occurring dibenzodiazepine BU-4664L and its derivatives. Bioorg. Med. Chem. Lett. 20, 963-965 (2010).

4 Miyanaga, S., Sakurai, H., Saiki, I., Onaka, H. \& Igarashi, Y. Synthesis and evaluation of myxochelin analogues as antimetastatic agents. Bioorg. Med. Chem. 17, 2724-2732 (2009).

5 Igarashi, Y. et al. Antitumor anthraquinones from an endophytic actinomycete Micromonospora lupini sp nov.. Bioorg. Med. Chem. Lett. 17, 3702-3705 (2007).

6 McBrien, K. D. et al. Rakicidins, new cytotoxic lipopeptides from Micromonospora sp Fermentation, isolation and characterization. J. Antibiot. 48, 1446-1452 (1995).

$7 \mathrm{Hu}, \mathrm{J}-\mathrm{F}$. et al. Rakicidin C, a new cyclic depsipeptide from Streptomyces sp. Eur. J. Org. Chem. 3353-3356 (2000).

8 Nishioka, H., Nakajima, S., Nagashima, M., Kojiri, K. \& Suda, H. (Banyu Pharmaceutical Co., Ltd.). BE-43547 series substances, their manufacture with Streptomyces species, and their use as antitumor agents. JP 10147594 A 19980602 (1998).

9 Igarashi, M. et al. Vinylamycin, a new depsipeptide antibiotic, from Streptomyces sp. J. Antibiot. 59, 873-879 (1999).

10 Saito, K. I., Oku, T., Ata, N., Miyashiro, H., Hattori, M. \& Saiki, I. A modified and convenient method for assessing tumor cell invasion and migration and its application to screening for inhibitors. Biol. Pharm. 20, 345-348 (1997).

11 Igarashi, Y., Miyanaga, S., Onaka, H., Takeshita, M. \& Furumai, T. Revision of the structure assigned to the antibiotic BU4664L from Micromonospora. J. Antibiot. 58, 350-352 (2005).

Supplementary Information accompanies the paper on The Journal of Antibiotics website (http://www.nature.com/ja) 